University of Wollongong

Research Online

Faculty of Engineering and Information

Faculty of Engineering and Information

Sciences - Papers: Part A

Sciences

2013

Enhancing impact fracture toughness and tensile properties of a microalloyed cast steel by hot forging and post-forging heat treatment processes

Jingwei Zhao

University of Wollongong, jzhao@uow.edu.au

Zhengyi Jiang

University of Wollongong, jiang@uow.edu.au

Chong Soo Lee

Pohang University of Science and Technology, cslee@postech.ac.kr

Follow this and additional works at: https://ro.uow.edu.au/eispapers

Part of the Engineering Commons, and the Science and Technology Studies Commons

Research Online is the open access institutional repository for the University of Wollongong. For further information contact the UOW Library: research-pubs@uow.edu.au 


\title{
Enhancing impact fracture toughness and tensile properties of a microalloyed cast steel by hot forging and post-forging heat treatment processes
}

\begin{abstract}
In the present work, the effects of hot forging and post-forging heat treatment on the impact fracture toughness and tensile properties of a microalloyed cast steel were investigated. Mechanical tests were used to evaluate the room temperature impact fracture toughness and tensile properties of the steel. The resulting microstructures were analysed by optical microscope (OM), scanning electron microscope (SEM) and transmission electron microscope (TEM). The extraction replica technology was used to investigate the characterisation of complex precipitates formed during heat treatment. The obtained results showed that the coarse-grained microstructure of the forged specimen was significantly refined after post-forging heat treatment. Presence of complex precipitates had a favourable effect on the formation of refined austenite grains, and consequently refined final microstructure. Hot forging was beneficial to enhance the impact fracture toughness and tensile properties of the microalloyed cast steel. After $920^{\circ} \mathrm{C}$-treatment followed by air cooling, the impact energy of the forged specimen was significantly increased from 19.3 to $208.3 \mathrm{~J}$, and further enhancement in tensile properties was obtained. The enhanced impact fracture toughness and tensile properties of the microalloyed cast steel after hot forging and post-forging heat treatment were closely related to the refined and homogenised ferritic-pearlitic microstructure.
\end{abstract}

\section{Keywords}

properties, tensile, toughness, fracture, processes, treatment, heat, post, forging, hot, impact, steel, enhancing, cast, microalloyed

\section{Disciplines \\ Engineering | Science and Technology Studies}

\section{Publication Details}

Zhao, J., Jiang, Z. \& Lee, C. Soo. (2013). Enhancing impact fracture toughness and tensile properties of a microalloyed cast steel by hot forging and post-forging heat treatment processes. Materials and Design, 47 227-233. 


\title{
Enhancing impact fracture toughness and tensile properties of a microalloyed cast steel by hot forging and post-forging heat treatment processes
}

\author{
Jingwei Zhao ${ }^{\mathrm{a}}$, Zhengyi Jiang ${ }^{\mathrm{a}}$, Chong Soo Lee ${ }^{\mathrm{b}, *}$
}

${ }^{a}$ School of Mechanical, Materials and Mechatronic Engineering, University of Wollongong, NSW 2522, Australia

${ }^{\mathrm{b}}$ Graduate Institute of Ferrous Technology, Pohang University of Science and Technology, Pohang 790-784, Republic of Korea

\begin{abstract}
In the present work, the effects of hot forging and post-forging heat treatment on the impact fracture toughness and tensile properties of a microalloyed cast steel were investigated. Mechanical tests were used to evaluate the room temperature impact fracture toughness and tensile properties of the steel. The resulting microstructures were analysed by optical microscope (OM), scanning electron microscope (SEM) and transmission electron microscope (TEM). The extraction replica technology was used to investigate the characterisation of complex precipitates formed during heat treatment. The obtained results showed that the coarse-grained microstructure of the forged specimen was significantly refined after post-forging heat treatment. Presence of complex precipitates had a favourable effect on the formation of refined austenite grains, and consequently refined final microstructure. Hot forging was beneficial to enhance the impact fracture toughness and tensile properties of the microalloyed cast steel. After $920^{\circ} \mathrm{C}$-treatment followed by air cooling, the impact energy of the forged specimen was significantly increased from 19.3 to $208.3 \mathrm{~J}$, and further enhancement in tensile properties was obtained. The enhanced impact fracture toughness and tensile properties of the microalloyed cast steel after hot forging and post-forging heat treatment were closely related to the refined and homogenised ferritic-pearlitic microstructure.
\end{abstract}

Keywords: Microalloyed steel; Forging; Heat treatment; Fracture toughness; Tensile properties

\footnotetext{
* Corresponding author. Tel.: +82-54-279-2141; Fax: +82-54-279-2399.

E-mail addresses: cslee@postech.ac.kr (C.S. Lee), jwzhaocn@gmail.com (J. Zhao).
} 


\section{Introduction}

The demand for new materials that provide excellent structural performances while reducing weight and being cost-effectively manufactured is increasing. For applications with good mechanical properties requirements, microalloyed steels have been widely used [1,2]. Microalloyed steels are designed to provide better combinations of excellent fracture toughness and high strength than conventional carbon steels. Microalloyed steels trace their origin to the weldable unalloyed constructional steels containing up to $0.2 \%$ C and 1.8\% Mn [3]. Small amounts of titanium (Ti), niobium (Nb) and vanadium (V) are introduced into these steels in the amount up to about 0.1 mass percent. The dispersive particles of the MX (M-Nb, Ti, and V; X-N and C) interstitial phases formed in the properly selected hot working conditions offer an important cost-effective approach to austenite grain size controlling and strengthening [4].

The work of Najafi [5] and Rassizadehghani [6] indicated that good combinations of strength and ductility of low-carbon cast steels can be achieved by microalloying additions. However, microalloying significantly decreased the impact toughness and led to the dominance of cleavage facets in the fracture surfaces. Cast steel products are produced by casting methods. Casting is a solidification process. Therefore, the microstructure can be finely tuned, such as grain structure, phase transformations and precipitation. However, defects such as shrinkage porosity, cracks and segregation are also intimately linked to solidification [7]. These defects can lead to lower mechanical properties. For eliminating such defects and achieving the desired mechanical properties, a subsequent hot working is often required before the steels can be applied. Steels used for structures, machine and vehicle parts are traditionally produced by hot forging, and the required properties are obtained by quenching and tempering treatments. This multi-stage process extends production time and leads to higher production costs. Instead, a simple process of hot forging followed by air cooling has been successfully developed on microalloyed cast steels to realise cost savings [8]. The 
air-cooled microstructures of microalloyed forging steels, in contrast to the martensite of quenched and tempered steels, are generally composed of ferrite and pearlite [9]. Since the strength improvement of the microalloyed ferritic-pearlitic steels mainly depends on the increment of pearlite volume fraction, ferrite grain refinement, solid solution and precipitation strengthening, it is limited to obtain a higher level of strength, leading to an obstacle to the development of its potential uses [10]. Krauss [11] has shown that microalloyed forging steels with the same hardness have much lower fracture toughness compared to highly quenched and tempered steels. Consequently, the application of microalloyed forging steels has often been limited based on fracture toughness consideration at the required strength level [12].

In contrast to those studies performed on direct-cooled microalloyed forging steels [13], investigation with purpose of improving both impact fracture toughness and tensile properties of microalloyed cast steels by focusing on hot forging and as well as post-forging heat treatment conditions has been rare. For broadening the application of microalloyed forging steels, it is essential to study the mechanical properties of microalloyed steels in both hot forging and post-forging heat treatment conditions in order to find the optimal process correlated with the best combination of excellent fracture toughness and mechanical properties. In the present study, the effects of hot forging and post-forging heat treatment on the mechanical properties of a microalloyed cast steel were investigated. This study aims to acquire the best combination of excellent impact fracture toughness and tensile properties of the steel through controlled hot forging and post-forging heat treatment processes. The research has immediate practical applications, and the outcomes can be successfully applied in steel manufacturing industries.

\section{Experimental procedure}

The material used in this study was a microalloyed cast steel. The chemical compositions are shown in Table 
1. The cast steel was heated to $1230^{\circ} \mathrm{C}$ for $1 \mathrm{~h}$ austenitisation and then hot forged to be a cube with section size of $140 \mathrm{~mm} \times 140 \mathrm{~mm}$ and height of $400 \mathrm{~mm}$ followed by air cooling. The final forging temperature was controlled to be higher than $950^{\circ} \mathrm{C}$ (Fig. 1). Prior to heat treatment, dilatometer tests were carried out to determine the austenitisation starting $\left(A_{\mathrm{c} 1}\right)$ and finishing $\left(A_{\mathrm{c} 3}\right)$ temperatures in heating process. For annealing heat treatment, two groups of rectangular specimens with sizes of $11 \mathrm{~mm} \times 11 \mathrm{~mm} \times 60 \mathrm{~mm}$ and $11 \mathrm{~mm} \times 11$ $\mathrm{mm} \times 110 \mathrm{~mm}$ respectively were cut from the forged piece. Specimens were heat treated at $840,860,880$, 900, 920 and $950^{\circ} \mathrm{C}$ for $1 \mathrm{~h}$ using an electric furnace in laboratory followed by air and furnace cooling, as illustrated in Fig. 1.

Specimens were metallographically polished and etched with $2 \%$ nital solution for microstructural observation by an OLYMPUS BX51M optical microscope (OM). Slightly overetched specimens were examined under JEOL JSM-6300F field-emission scanning electron microscope (FE-SEM) to present the detailed microstructure at relatively high resolution. For observing prior austenite grain boundaries, specimens were heated to $1230^{\circ} \mathrm{C}$ and various annealing temperatures for $1 \mathrm{~h}$ followed by water quenching. The water quenched specimens were etched with a "picric acid $+\mathrm{FeCl}_{3}+$ dodecyl benzene sulfonic acid sodium salt" solution to reveal prior austenite grain boundaries, and then observed by OM. To examine the characteristic and composition of precipitates, extraction replicas as well as thin foils mounted on Cu grids specimens were prepared by the following steps: (i) polish samples with $\mathrm{SiC}$ sand papers; (ii) release surface residual stress of the samples with a "methanol + acetylaceton + tetramethylammonium chloride" solution; (iii) do the carbon coating using Vacuum Evaporator JEE-420, JEOL; (iv) separate the carbon foils with a "HCl + methylalcohol” solution; and (v) mount the thin foils on $\mathrm{Cu}$ grids. Replica specimens were analysed using energy dispersive X-ray spectroscopy (EDS) method on JEOL JEM-2100F transmission electron microscope (TEM) operated at $200 \mathrm{kV}$. 
Standard Charpy impact specimens were machined according to ASTM E 23. The Charpy V-notched specimens with cross section of $10 \mathrm{~mm} \times 10 \mathrm{~mm}$, length of $55 \mathrm{~mm}$, notch angle of $45^{\circ}$ and notch depth of 2 mm were employed to study the room temperature impact fracture toughness on a Zwick/Roell impact tester. Tensile specimens were prepared according to ASTM E 8M (Gauge length $30 \mathrm{~mm}$, gauge diameter $6 \mathrm{~mm}$ ). Tensile tests were performed on INSTRON 8801 at room temperature with strain rate of $5 \times 10^{-3} \mathrm{~s}^{-1}$. The resulting stress-strain curves were analysed to determine the yield strength (YS, $0.2 \%$ proof stress) and ultimate tensile strength (UTS). Fracture surfaces of the tested specimens were examined on SEM using an accelerating voltage of $15 \mathrm{kV}$ to determine the failure mode.

\section{Experimental results}

\subsection{Microstructures}

Fig. 2 shows the OM structure of the as-cast specimen. As demonstrated, dendrite was caused during casting process. The microstructures of the forged specimens are shown in Fig. 3. It can be seen that the forged specimen consists mainly of coarse polygonal ferrite (PF) and pearlite, companied with small quantity of acicular ferrite (AF).

Fig. 4 shows the microstructures of the heat-treated specimens. It can be seen from Fig. 4a that ferrite non-uniformly distributes in the microstructure of the $840^{\circ} \mathrm{C}$-treated specimen. When the temperature is increased to $920^{\circ} \mathrm{C}$, the microstructure consists of equiaxed ferrite and pearlite, and the ferrite grain size distribution is very uniform (Fig. 4b). With further increasing temperature from 920 to $950^{\circ} \mathrm{C}$, abnormal growth of some grains occurs, as shown in Fig. 4c. Moreover, furnace cooling induces coarser grains in contrast to that followed by air cooling at the same temperature, as presented in Fig. 4b and d. According to 
Figs. $3 \mathrm{a}$ and $4 \mathrm{~b}$, it is apparent that $920^{\circ} \mathrm{C}$-treatment followed by air cooling has significantly decreased the pearlite colony size, and as well as refined and homogenised the microstructure. After determined by using circular intercept method according to ASTM E112, the average ferrite grain size of the $920^{\circ} \mathrm{C}$-treated specimen suffered from air cooling is obtained to be $10.0 \mu \mathrm{m}$.

\subsection{Impact fracture toughness and tensile properties}

The impact energies of the as-cast and forged specimens are obtained to be 5.4 and $19.3 \mathrm{~J}$, respectively, from Charpy impact tests. Obviously, the impact fracture toughness of the as-cast steel is very poor. Although the impact energy of the as-cast steel has been increased after hot forging, the fracture toughness level is still very low. Fig. 5 shows the dependence of impact energy on temperature of the specimens after $1 \mathrm{~h}$ heat treatment followed by both air and furnace cooling. It can be seen that the impact energy of the specimen subjected to air cooling is higher than that cooled in furnace. The impact energy of the air-cooled specimen increases gradually at first, then to a maximum value at the temperature of $920^{\circ} \mathrm{C}$, and it finally drops when the temperature is higher than $920^{\circ} \mathrm{C}$. The highest impact energy under air cooling condition is obtained to be $208.3 \mathrm{~J}$, which is about 38 times higher than that of the as-cast one.

The heat-treated specimen with the highest fracture toughness level was employed to do the tensile tests. Table 2 lists the tensile properties of the as-cast, forged and heat-treated specimens evaluated from room temperature tensile tests. It can be seen that both the tensile strength and strain have been significantly increased after hot forging. Post-forging heat treatment followed by air cooling induces further increase in YS and strain. Differently, heat treatment shows little effect on the increment of UTS.

\subsection{Fractography}


Selected fracture surfaces in the shear lip areas of some impact test specimens are demonstrated in Fig. 6. It can be seen in Fig. 6a that the fracture surface of the forged specimen is composed of cleavage facets and shear cracks, which indicates the brittle nature of fracture. The fracture mode has been remarkably changed after post-forging heat treatment. As shown in Fig. 6b, the fracture surface of the $920^{\circ} \mathrm{C}$-treated specimen followed by air cooling is composed of small, deep and uniformly distributed dimples, which shows a characteristic of ductile fracture. Larger dimples exist in the fracture surface when the specimen is heat treated at $950^{\circ} \mathrm{C}$ in contrast to that at $920^{\circ} \mathrm{C}$, as shown in Fig. 6c.

Fig. 7a, b and c show the tensile fracture morphologies of the as-cast, forged and $920^{\circ} \mathrm{C}$-treated specimens, respectively. As demonstrated in Fig. 7a, the as-cast specimen exhibits a brittle cleavage fracture. Although hot forging has changed the fracture mode, big and non-uniformly distributed dimples exist in the fracture surface (Fig. $7 \mathrm{~b}$ ). After $920^{\circ} \mathrm{C}$-treatment followed by air cooling, the fracture surface is still composed of dimples (Fig. 7c). Differently, the dimples are smaller and deeper, and the distribution of dimples is more uniform in contrast to that in the forged specimen, as shown in Fig. 7b and c. According to Fig. 7a, b and c, it is clear that post-forging heat treatment has a favourable effect on the generation of small, deep and uniformly distributed dimples after tensile tests.

\section{Discussion}

\subsection{Microstructural evolution}

Ferrite grain size is closely related to austenite grain size and cooling rate by the following relation [14]:

$$
d_{\alpha}=11.7+0.14 d_{\gamma}+37.7 R^{-1 / 2}
$$

where $d_{\alpha}$ is the ferrite grain size (mm), $d_{\gamma}$ is the austenite grain size (mm), and $R$ is the linear rate of cooling in degree centrifuged per minute. In this study, the cast steel was hot forged and then followed by air cooling, 
and the heat-treated specimens were cooled in air and furnace. Under the same air cooling condition, the ferrite grain sizes of both the hot forged and heat treated specimens should increase in linear manners with the austenite grain size based on Eq. (1).

According to the results of dilatometer tests, the $A_{\mathrm{c} 1}$ and $A_{\mathrm{c} 3}$ temperatures of the studied steel were determined as 766 and $903^{\circ} \mathrm{C}$, respectively. Holding specimens at temperatures higher than $903^{\circ} \mathrm{C}$ induces complete austenitisation, and prior austenite grain boundaries of the specimens water-quenched from these temperatures can be revealed. Fig. 8a and b present the prior austenite grains of the water-quenched specimens after holding at 920 and $1230^{\circ} \mathrm{C}$ for $1 \mathrm{~h}$, respectively. As can be seen in Fig. 8a, the austenite grain size of $920^{\circ} \mathrm{C}$-treated specimen is small. Increment of austenitising temperature induces coarser austenite grains, as shown in Fig. 8b. The average austenite grain sizes of the $920^{\circ} \mathrm{C}$ - and $1230^{\circ} \mathrm{C}$-treated specimens were determined as 14.6 and $158.6 \mu \mathrm{m}$, respectively, by using circular intercept method according to ASTM E112. Based on Eq. (1), finer ferrite grains are expected to form in the $920^{\circ} \mathrm{C}$-treated specimen than that in the $1230^{\circ} \mathrm{C}$-treated specimen. According to Figs. 3a, $4 \mathrm{~b}$ and 8 , it is apparent that refinement of austenite grain size in microalloyed steels is critical in producing fine-grained ferritic-pearlitic microstructures.

The addition of microalloying elements can form carbides, nitrides or carbonitrides. These precipitates very effectively restrict austenite grain growth [15]. From a processing standpoint, the forged steels are reheated to a high austenitising temperature and then deformed at elevated temperature prior to transformation during air cooling. Heat-treated steels are held at lower temperatures before cooling to produce the final microstructure. The reheating temperature, in combination with the steel composition, controls the extent of microalloying elements dissolution, and consequently, the amount of microalloying elements addition available for subsequent precipitation. The dissolution and precipitation behaviour of the microalloying 
elements strongly influence the austenite grain size of microalloyed steels.

Fig. 9 shows the characteristic and composition of precipitates in the specimens held at 920 and $1230^{\circ} \mathrm{C}$ for 1 h. When holding at $920^{\circ} \mathrm{C}$, coarse precipitates with irregular shape are found, as shown in Fig. 9a. Additional EDS analysis shows that the irregular particles contain $\mathrm{Ti}, \mathrm{Nb}$ and $\mathrm{V}$ elements (Fig. 9c). Based on the compositions given in Table 1 and previous work [16,17], the precipitates are probably $\mathrm{Ti}$, $\mathrm{Nb}$ and $\mathrm{V}$ carbides/nitrides (or carbonitrides). Moreover, the spectrum shows high $\mathrm{Cu}, \mathrm{Si}$ and $\mathrm{O}$ peaks. The $\mathrm{Cu}$ peaks are from the $\mathrm{Cu}$ grid when preparing the replica specimens. The Si and O peaks may correspond to silica or silicic acid formed by oxidation and hydration of the Si in the steel during the electrochemical extraction [18]. With increasing austenitising temperature from 920 to $1230^{\circ} \mathrm{C}$, the size of precipitates decreases, and just square precipitates exist in the specimen, as shown in Fig. 9b. The result of EDS analysis shows that these square precipitates only contain $\mathrm{Ti}$ and $\mathrm{Nb}$, and the content of $\mathrm{Nb}$ in the precipitates is very low in contrast to that in the precipitates of the $920^{\circ} \mathrm{C}$-treated specimen, as shown in Fig. 9c and d.

In microalloyed steels, vanadium precipitates have the lowest stability and readily dissolve on heating to forging temperatures. Niobium precipitates have higher stability, and therefore may be harder to dissolve during heating to forging temperatures. Titanium nitride TiN is stable at very high temperatures, and it usually precipitates in liquid steel or at high temperatures in the austenite regime [19]. According to the analysis results of Fig. 9, it is probable that $\mathrm{TiN}$ is the initial precipitate, and $\mathrm{Nb}$ and $\mathrm{V}$ mostly form on the outside layer of $\mathrm{TiN}$ to be a complex precipitate in the $920^{\circ} \mathrm{C}$-treated specimen (Fig. 9a and c). In fact, because $\mathrm{Ti}, \mathrm{Nb}$ and $\mathrm{V}$ carbides, nitrides or carbonitrides have similar crystal structures, co-precipitation is very common in multi-microalloyed steels $[16,17]$. When the reheating temperature is elevated to $1230^{\circ} \mathrm{C}$, all $\mathrm{V}$ - and most Nb-containing particles dissolve from the outside layer of the complex precipitates and return to 
the austenite solid solution. Subsequently, the size of precipitates decreases, as shown in Fig. 9b. According to previous work [20], decrement of the precipitates size is associated with significant reduction of the amount of precipitates when the austenitising temperature is increased. Therefore, based on Figs. 8 and 9, it can be deduced that complex precipitates have a favourable effect on the formation of refined austenite grains. Coarsening of austenite grains at $1230^{\circ} \mathrm{C}$ should be attributed to the dissolution of V- and Nb-containing particles and the reduction of the amount of precipitates.

For the heat-treated specimens, heat treatment at temperatures lower than $903^{\circ} \mathrm{C}$ induces incomplete austenitisation, leading to non-uniform distribution of ferrite grains. In contrast to the $920^{\circ} \mathrm{C}$-treated specimen suffered from air cooling, growth of ferrite grains in the specimens heat-treated at high autenitising temperature or cooled in furnace is considered to be caused by the coarsening of austenite grains.

\subsection{Enhancement of impact fracture toughness and tensile properties}

There are three major property requirements for microalloyed steels: high yield strength, low impact transition temperature and good weldability [21]. Both the high yield strength and low impact transition temperature can be achieved through ferrite grain refinement. The quantitative relationship between the yield strength and grain size is known as the classic Hall-Petch equation [22,23]:

$$
\mathrm{YS}=\sigma_{0}+k_{y} d^{-1 / 2}
$$

where YS is the yield strength, $\sigma_{0}$ is the friction stress needed to move individual dislocations, $k_{y}$ is a constant (often referred to as the Hall-Petch slope and is material dependent), and $d$ is the average grain size ( $d$ refers to the ferrite grain size in ferritic-pearlitic steels). According to Eq. (2), fine-grained structure has a pronounced effect on the increment of yield strength. In another supporting work, similar conclusion was obtained by Pickering [24] with an empirical equation for ferritic-pearlitic steels under $0.25 \%$ C. 
Grain refinement in microalloyed steels simultaneously produces increased strength, fracture toughness and ductility, without affecting weldability, as shown in Fig. 10 [21]. The fracture toughness, YS and strain of the heat-treated specimens suffered from air cooling are significantly enhanced in contrast to the forged specimens. According to Figs. 3 and 4, and as well as the above analysis, these enhanced properties are closely related to the remarkable ferrite grain refinement.

During hot forging process, plastic deformation produces an increase in the number of dislocations, resulting in a higher state of internal stress. In V-microalloyed forging steels, ferrite nucleates and grows not only on austenite grain boundaries but also intragranularly on MnS particles within austenite grains. The resulting intragranularly formed AF (Fig. 3a) breaks up the massive pearlitic structures formed in a coarse-grained austenite and improve strength and fracture toughness [25,26]. After heat treatment, the internal stress was relieved from the forged steel, and the AF-containing microstructure was replaced by homogenised ferritic-pearlitic structure. Therefore, no significant increment in UTS after heat treatment in contrast to the forged specimens even though refine-grained microstructure, which can improve the strength, is obtained.

Among the heat-treated specimens, heat treatment at temperatures lower than $903^{\circ} \mathrm{C}$ induces incomplete austenitisation, leading to non-uniform distribution of ferrite after air cooling. Coarser ferrite grains will be caused if the austenitising temperature is higher than $920^{\circ} \mathrm{C}$ due to the increase of austenite grain size with temperature. These will consequently reduce the fracture toughness. Under furnace cooling condition, the coarsening of ferrite grains during the very slow cooling process is responsible for the reduced impact energy.

\section{Conclusions}


In the present study, the enhancement of impact fracture toughness and tensile properties of a microalloyed cast steel by hot forging and post-forging heat treatment processes was investigated. Following conclusions are drawn from the present work:

1. Under hot forging condition, the specimen exhibits a mixed microstructure of coarse polygonal ferrite, pearlite and small quantity of acicular ferrite. $920^{\circ} \mathrm{C}$-treatment followed by air cooling significantly decreased the pearlite colony size, and as well as refined and homogenised the microstructure.

2. The morphology and composition of complex precipitates vary with austenitising temperatures. Presence of complex precipitates has a favourable effect on the formation of refined austenite grains at $920^{\circ} \mathrm{C}$. Coarsening of austenite grains at $1230^{\circ} \mathrm{C}$ is attributed to the dissolution of $\mathrm{V}$ - and $\mathrm{Nb}$-containing particles and the reduction of the amount of precipitates.

3. Hot forging is beneficial to increase the impact fracture toughness and tensile properties of the microalloyed cast steel. After $920^{\circ} \mathrm{C}$-treatment followed by air cooling, the impact energy of the forged specimen is significantly increased from 19.3 to $208.3 \mathrm{~J}$, and further enhancement in YS and strain is obtained.

4. In contrast to the forged specimen, the increased impact energy, YS and strain after post-forging heat treatment are closely related to the refined ferritic-pearlitic microstructure. Differently, grain refinement shows little effect on the increment of UTS. The impact fracture toughness and tensile properties of the microalloyed cast steel are significantly enhanced by obtaining the refined and homogenised microstructure after hot forging and post-forging heat treatment processes. 


\section{References}

[1] Vervynckt S, Thibaux P, Verbeken K. Effect of niobium on the microstructure and mechanical properties of hot rolled microalloyed steels after recrystallization-controlled rolling. Met Mater Int 2012;18:37-46.

[2] Cruz MGH, Viecelli A. A methodology for replacement of conventional steel by microalloyed steel in bus tubular structures. Mater Des 2008;29:539-45.

[3] Adamczyk J. Development of the microalloyed constructional steels. J Achievements Mater Manuf Eng 2006;14:9-20.

[4] Show BK, Veerababu R, Balamuralikrishnan R, Malakondaiah G. Effect of vanadium and titanium modification on the microstructure and mechanical properties of a microalloyed HSLA steel. Mater Sci Eng A 2010;527:1595-604.

[5] Najafi H, Rassizadehghani J, Asgari S. As-cast mechanical properties of vanadium/niobium microalloyed steels. Mater Sci Eng A 2008;486:1-7.

[6] Rassizadehghani J, Najafi H, Emamy M, Eslami-Saeen G. Mechanical properties of V-, Nb-, and Ti-bearing as-cast microalloyed steels. J Mater Sci Technol 2007;23:779-84.

[7] Zhao J, Lee JH, Kim YW, Jiang Z, Lee CS. Enhancing mechanical properties of a low-carbon microalloyed cast steel by controlled heat treatment. Mater. Sci Eng A 2013;559:427-35.

[8] Honeycombe RMK, Bhadeshia HKDH. Steels-Microstructure and Properties. 2nd ed. London: Edward Arnold; 1995.

[9] Ceschini L, Marconi A, Martini C, Morri A, Schino AD. Tensile and impact behaviour of a microalloyed medium carbon steel: effect of the cooling condition and corresponding microstructure. Mater Des 2013;45:171-78.

[10] Zhao J, Kim YW, Lee JH, Lee JM, Chang HS, Lee CS. Effect of tungsten addition on the mechanical properties and corrosion resistance of S355NL forging steel. Met Mater Int 2012;18:217-23. 
[11] Krauss G. Steels: Processing, Structure, and Performance. Ohio: ASM International; 2005.

[12] Liu TJ. Modeling microstructural evolution of microalloyed forging steels during thermomechanical processing. Kingston: Queen’s University; 2001.

[13] Matlock DK, Krauss G, Speer JG. Microstructures and properties of direc-cooled microalloy forging steels. J Mater Process Technol 2001;117:324-8.

[14] Woodhead JH. Review of principles of microalloyed bar and forging steels. in: Krauss G, Banerjie SK, editors. Fundamentals of microalloying forging steels, Warrendale: TMS-AIME; 1987, p. 3-18.

[15] Craven AJ, He K, Baker TN. Complex heterogeneous precipitation in titanium-niobium microalloyed Al-killed HSLA steels - I. (Ti,Nb)(C,N) particles. Acta Mater 2000;48:3857-68.

[16] Poths RM, Higginson RL, Palmiere EJ. Complex precipitation behaviour in a microalloyed plate steel. Scr Mater 2001;44:147-51.

[17] Scott CP, Chaleix D, Barges P, Rebischung V. Quantitative analysis of complex carbo-nitride precipitates in steels. Scr Mater 2002;47:845-9.

[18] Gurry RW, Christakos J, Stricker CD. Electrolytic extraction of carbides from carbon steel. Trans ASM 1958;50:105-28.

[19] Gladman T. The physical metallurgy of microalloyed steels. London: The Institute of Materials; 1997.

[20] Fu RD, Wang TS, Zhou WH, Zhang WH, Zhang FC. Characterization of precipitates in a 2.25Cr-1Mo-0.25V steel for large-scale cast-forged products. Mater Charact 2007;58:968-73.

[21] Skobir DA. High-strength low-alloy (HSLA) steels. Mater Technol 2011;45:295-301.

[22] Hall EO. The deformation and ageing of mild steel: III Discussion of results. Proc Phys Soc London 1951;B64:747-53..

[23] Petch NJ. The cleavage of polycrystals. J Iron Steel Inst 1953;174:25-8.

[24] Pickering FB. Towards improved toughness and ductility. Kyoto: Climax Molybdenum Company 
Synopsium; 1971.

[25] Ochi T, Takahashi T, Takada H. Improvement of the Toughness of Hot Forged Products through Intra-granular Ferrite Formation, in 30th Mechanical Working and Steel Processing Conference Proceedings, Vol. XXVI, Warrendale: ISS-AIME; 1988, p. 65-72.

[26] Kim YM, Lee H, Kim NJ. Transformation behavior and microstructural characteristics of acicular ferrite in linepipe steels. Mater Sci Eng A 2008;78:361-70. 


\section{Figure Captions:}

Fig. 1. Schematic illustration of the hot forging and post-forging heat treatment processes.

Fig. 2. OM structure of the as-cast specimen.

Fig. 3. Microstructures of the forged specimens. (a) OM structure, and (b) SEM of pearlite.

Fig. 4. Microstructures of the heat-treated specimens subjected to (a,b,c) air and (d) furnace cooling. (a) $840^{\circ} \mathrm{C}$, (b,d) $920^{\circ} \mathrm{C}$, and (c) $950^{\circ} \mathrm{C}$.

Fig. 5. Charpy impact energies of the heat-treated specimens.

Fig. 6. Fracture morphologies of the specimens after Charpy impact tests. (a) Forged, (b) $920^{\circ} \mathrm{C}+$ Air cooling, and (c) $950^{\circ} \mathrm{C}+$ Air cooling.

Fig. 7. Fracture morphologies of the specimens after tensile tests. (a) As-cast, (b) Forged, and (c) $920^{\circ} \mathrm{C}+$ Air cooling.

Fig. 8. Prior austenite grains of the water-quenched specimens after holding at (a) $920^{\circ} \mathrm{C}$ and (b) $1230^{\circ} \mathrm{C}$ for $1 \mathrm{~h}$.

Fig. 9. Extraction replicas exhibiting complex precipitates observed in the specimens held at (a,c) $920^{\circ} \mathrm{C}$ and (b,d) $1230^{\circ} \mathrm{C}$ for 1 h. (a,b) Dark field images, and (c,d) EDS spectra.

Fig. 10. Effect of ferrite grain size on properties. 


\section{Table Captions:}

Table 1 Chemical compositions of the studied steel (wt.\%).

Table 2 Tensile properties of the specimens under different processing conditions. 


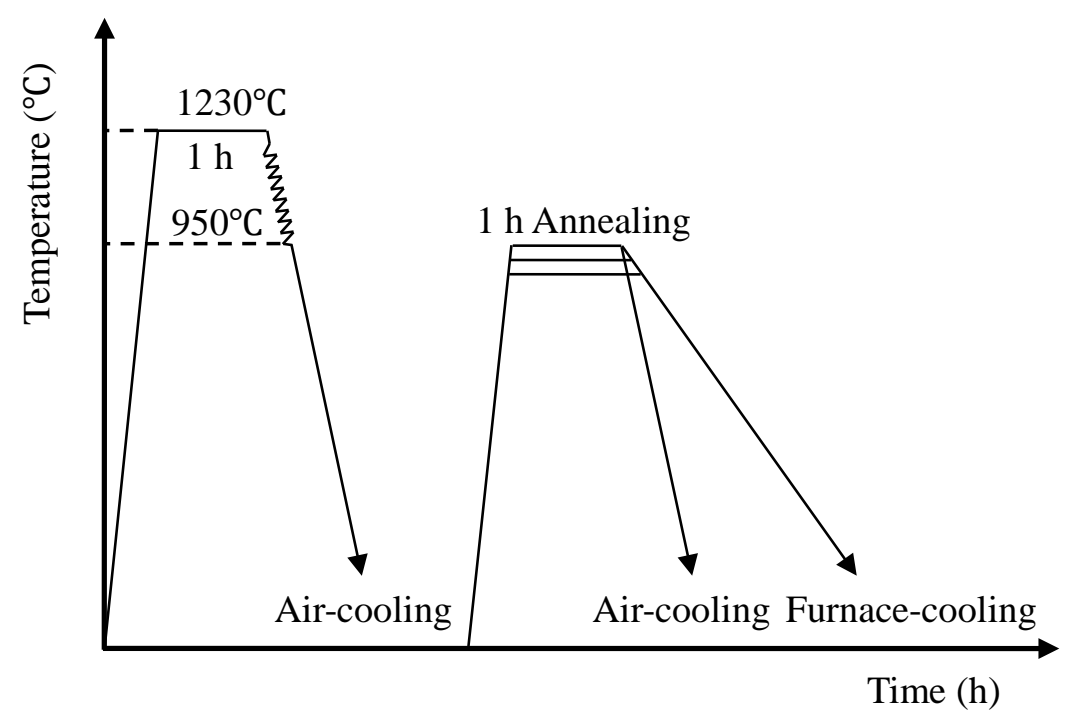

Fig. 1. Schematic illustration of the hot forging and post-forging heat treatment processes. 


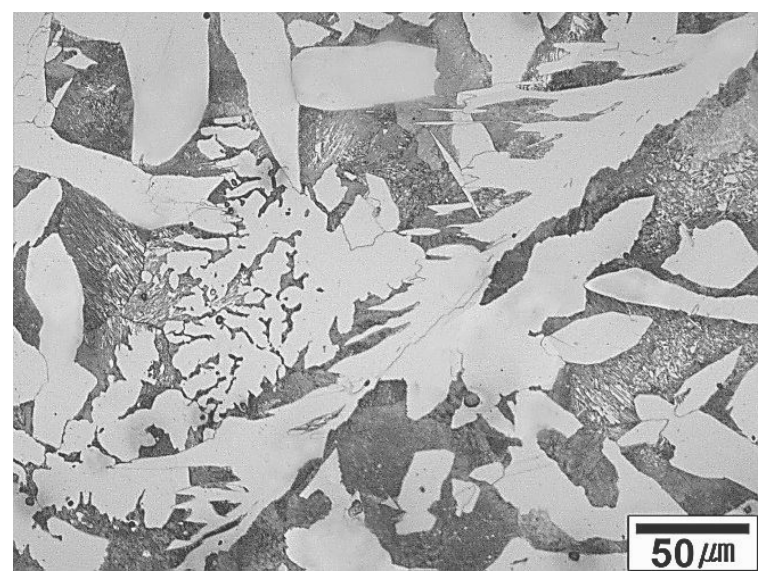

Fig. 2. OM structure of the as-cast specimen.
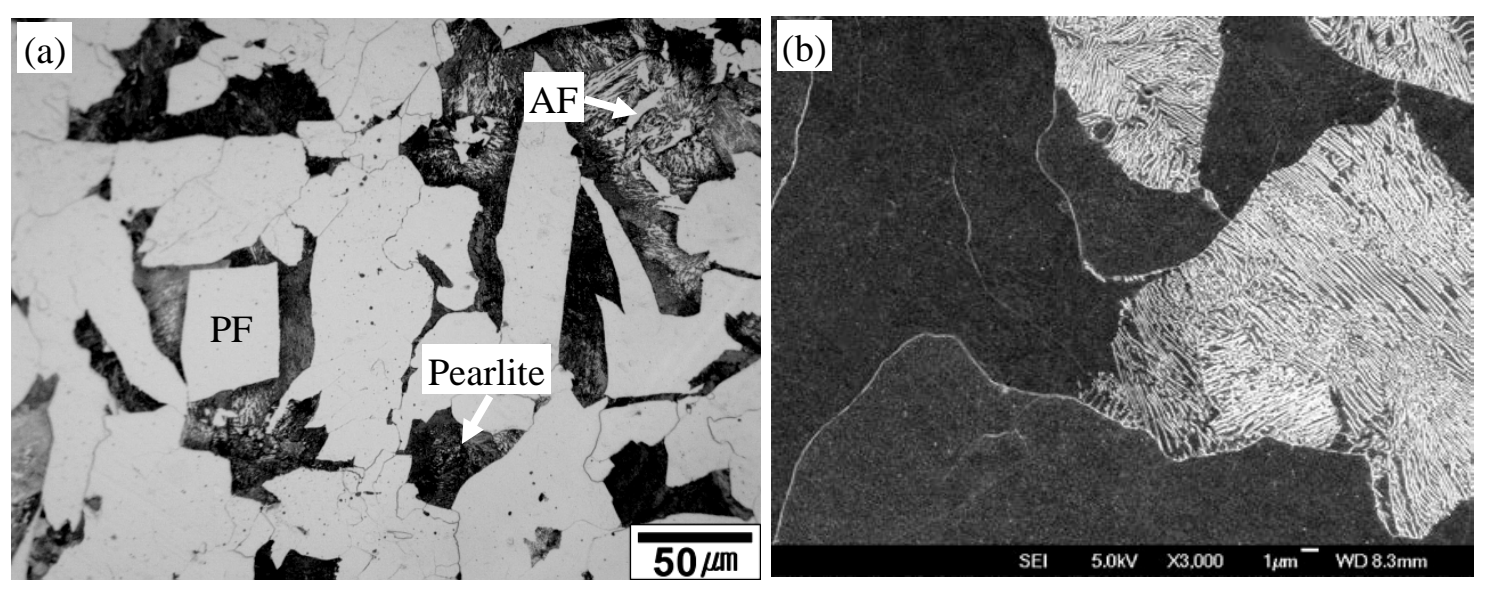

Fig. 3 Microstructures of the forged specimens. (a) OM structure, and (b) SEM of pearlite. 

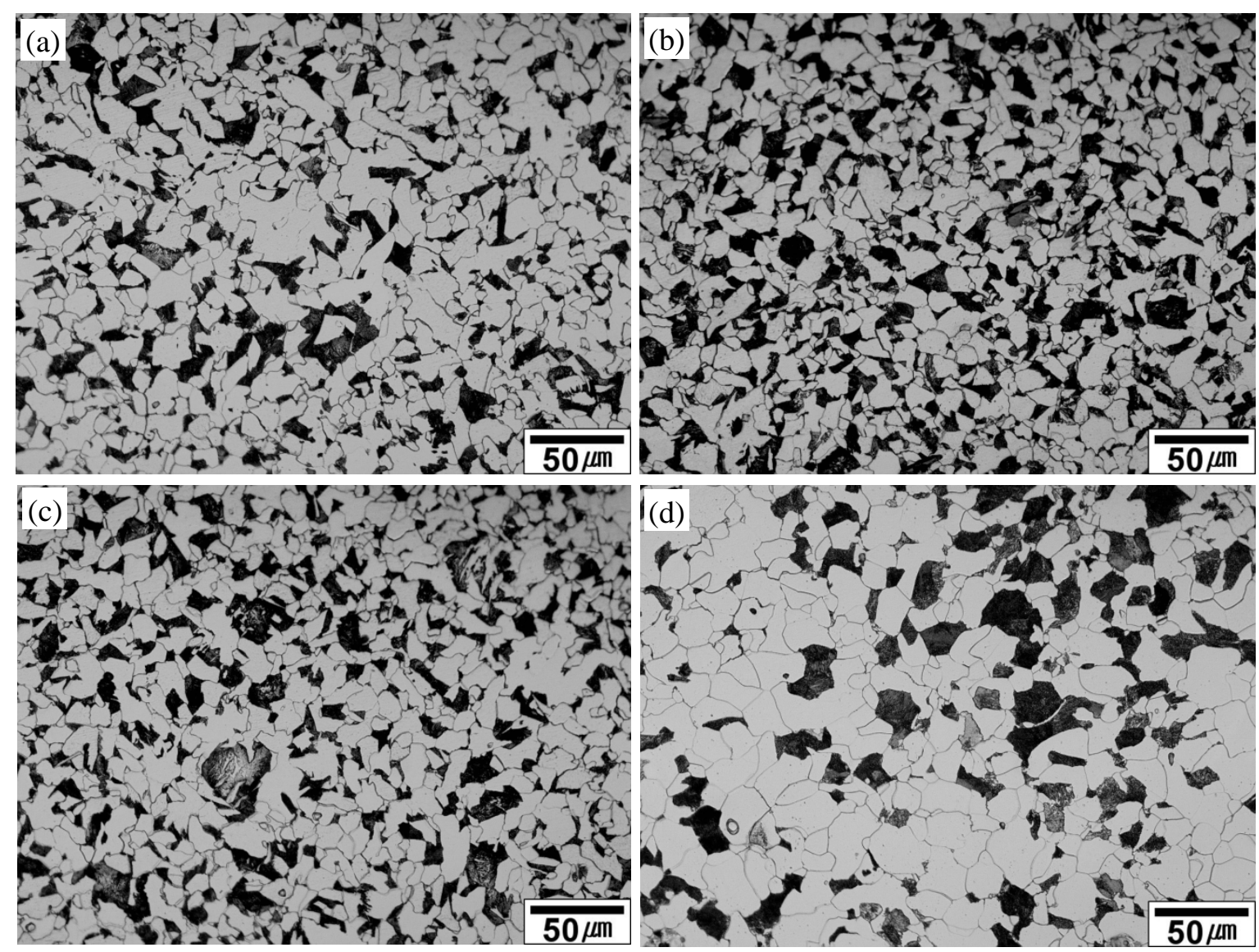

Fig. 4. Microstructures of the heat-treated specimens subjected to (a,b,c) air and (d) furnace cooling. (a) $840^{\circ} \mathrm{C}$, (b,d) $920^{\circ} \mathrm{C}$, and (c) $950^{\circ} \mathrm{C}$. 


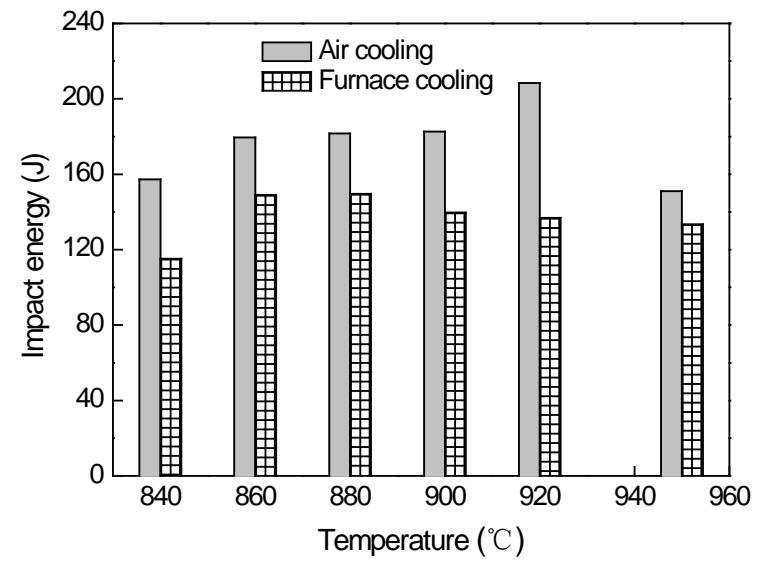

Fig. 5. Charpy impact energies of the heat-treated specimens.
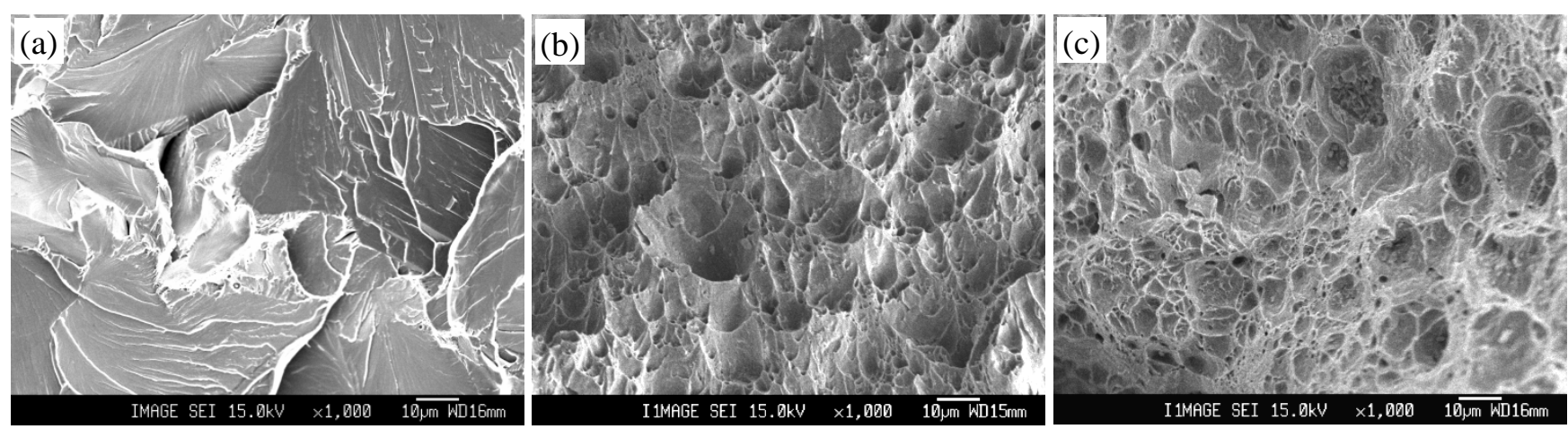

Fig. 6. Fracture morphologies of the specimens after Charpy impact tests. (a) Forged, (b) $920^{\circ} \mathrm{C}+$ Air cooling, and (c) $950^{\circ} \mathrm{C}+$ Air cooling. 

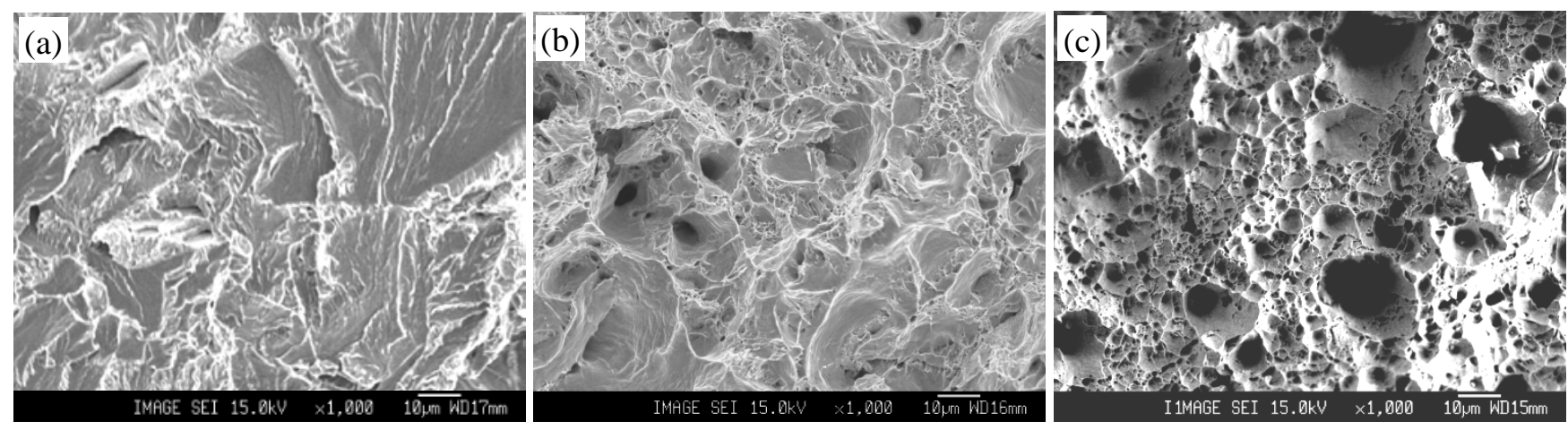

Fig. 7. Fracture morphologies of the specimens after tensile tests. (a) As-cast, (b) Forged, and (c) $920^{\circ} \mathrm{C}+$ Air cooling.
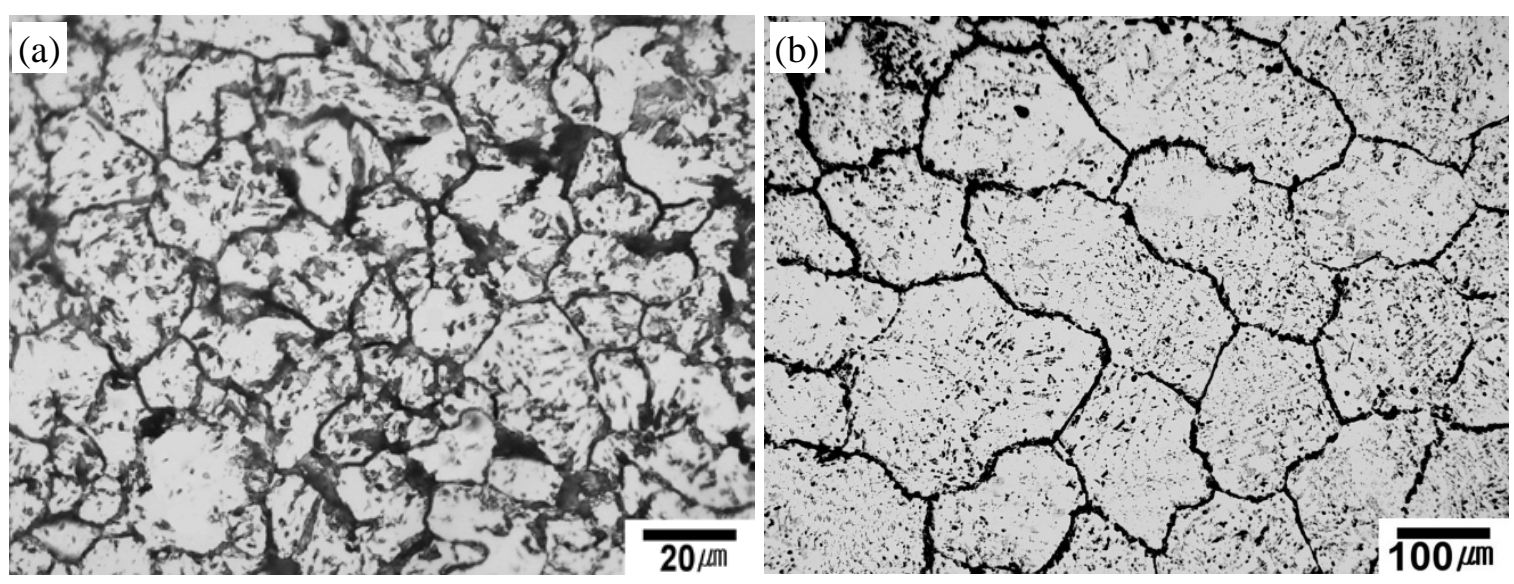

Fig. 8. Prior austenite grains of the water-quenched specimens after holding at (a) $920^{\circ} \mathrm{C}$ and (b) $1230^{\circ} \mathrm{C}$ for $1 \mathrm{~h}$. 

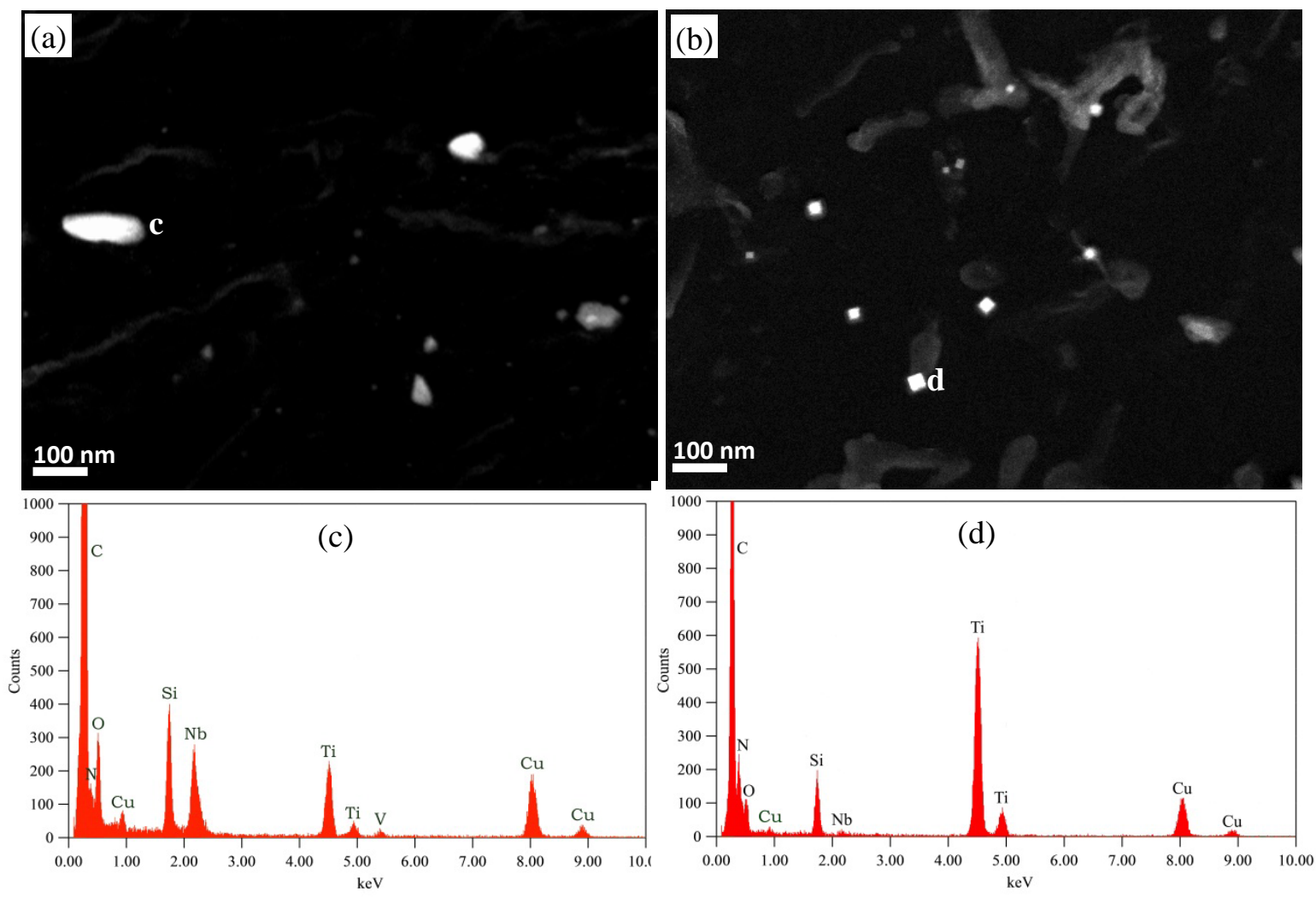

Fig. 9. Extraction replicas exhibiting complex precipitates observed in the specimens held at (a,c) $920^{\circ} \mathrm{C}$ and (b,d) $1230^{\circ} \mathrm{C}$ for 1 h. (a,b) Dark field images, and (c,d) EDS spectra.

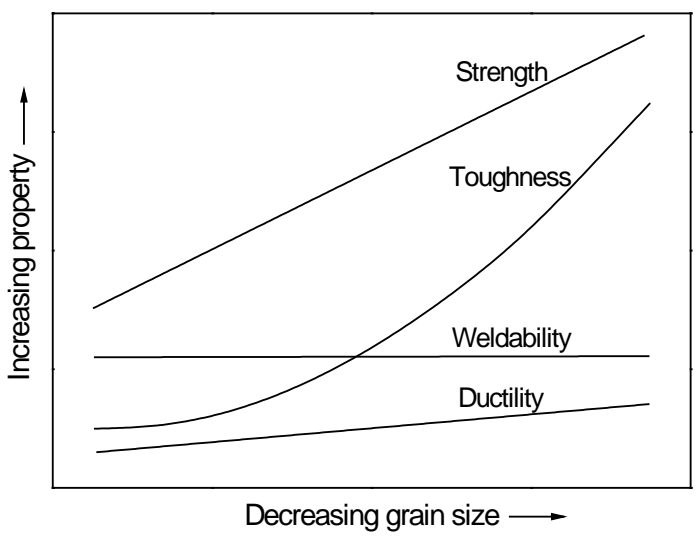

Fig. 10. Effect of ferrite grain size on properties. 
Table 1 Chemical compositions of the studied steel (wt.\%).

\begin{tabular}{ccccccccccccc}
\hline $\mathrm{C}$ & $\mathrm{Mn}$ & $\mathrm{Cr}$ & $\mathrm{Ni}$ & $\mathrm{Cu}$ & $\mathrm{Si}$ & $\mathrm{Al}$ & $\mathrm{V}$ & $\mathrm{Nb}$ & $\mathrm{Ti}$ & $\mathrm{P}$ & $\mathrm{S}$ & $\mathrm{N}$ \\
\hline 0.17 & 1.2 & 0.1 & 0.02 & 0.02 & 0.47 & 0.02 & 0.01 & 0.02 & 0.02 & 0.01 & 0.01 & 0.006 \\
\hline
\end{tabular}

Table 2 Tensile properties of the specimens under different processing conditions.

\begin{tabular}{llll}
\hline Specimens & YS (MPa) & UTS (MPa) & Strain (\%) \\
\hline As-cast & 351.6 & 515.5 & 4.1 \\
Forged & 363.2 & 592.7 & 29.4 \\
$920^{\circ} \mathrm{C}+$ Air cooling & 390.1 & 593.2 & 35.0 \\
\hline
\end{tabular}

